\title{
In memoriam of Alexander Golovin (1939-2013)
}

\author{
O. Egorova ${ }^{1}$, T. Koetsier ${ }^{2}$, M. Ceccarelli ${ }^{3}$, H.-S. Yan $^{4}$, H. Kerle ${ }^{*, * *}$, and T. Chondros ${ }^{5}$ \\ ${ }^{1}$ Bauman Moscow State Technical University - MGTU, Department of Mechanical Engineering, \\ Egerskay Street, 5-2-13, 107014 Moscow, Russia \\ ${ }^{2}$ Vrije University of Amsterdam, Department of Mathematics, De Boelelaan 1081, \\ $1081 \mathrm{HV}$ Amsterdam, the Netherlands \\ ${ }^{3}$ LARM: Laboratory of Robotics and Mechatronics DICeM, University of Cassino and South Latium, \\ Via Di Biasio 43, 03043 Cassino (Fr), Italy \\ ${ }^{4}$ National Cheng Kung University, Department of Mechanical Engineering, 1 University Road, \\ Tainan, 701-01, Taiwan, China-Taipei \\ ${ }^{5}$ University of Patras, School of Engineering Mechanical Engineering and Aeronautics Department, \\ 26500 Patras, Greece \\ * formerly at: Universität Braunschweig, Institut für Werkzeugmaschinen und Fertigungstechnik, \\ Langer Kamp 19b, 38106 Braunschweig, Germany \\ ${ }^{* * *}$ retired
}

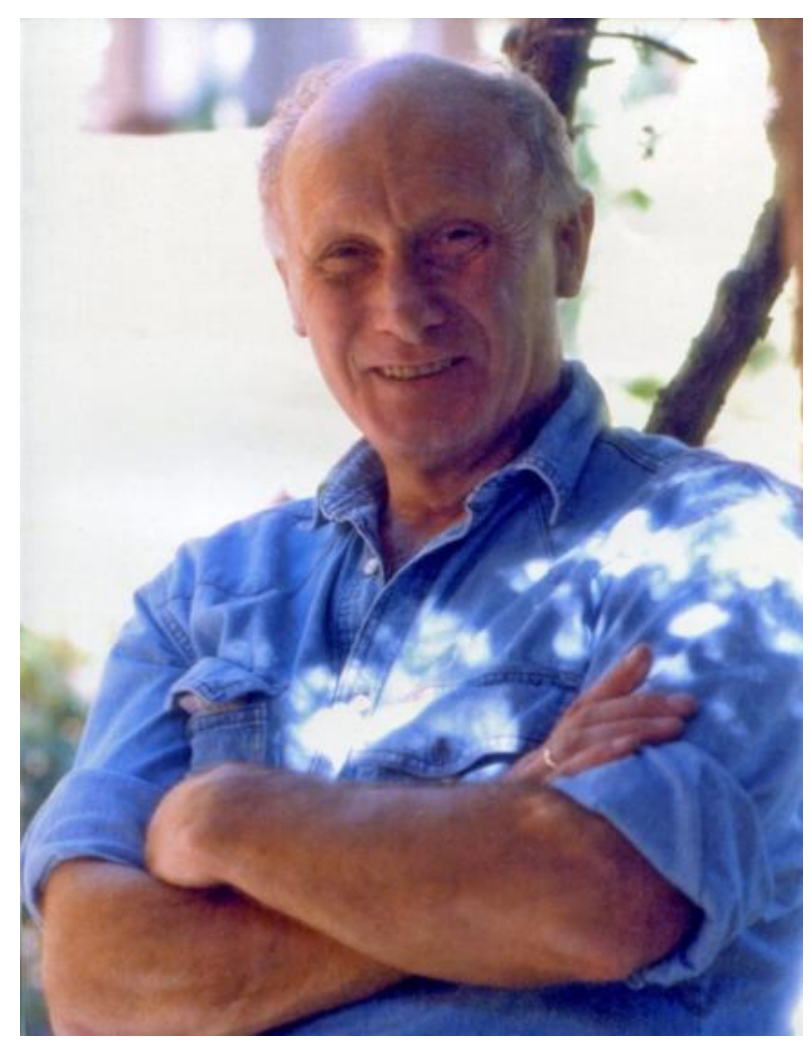

On Wednesday, 4 December 2013, our friend and colleague Alexander Golovin, professor of mechanical engineering at Bauman Moscow State Technical University within the Bauman School on Theory of Mechanisms and Machines, passed away at his home in Moscow. Alexander was born on 3 March 1939. He graduated as a mechanical engineer at the Bauman School in 1962. He became an assistant professor there in 1968 and associate professor in 1977. After having obtained his $\mathrm{PhD}$ in 1993, he became a full professor. He had a great passion for mountain climbing, being a master of the sport since his youth, and he climbed several mountains successfully. In 1988 he was a member of a group of five mountaineers that reached the top of Peak "7495", the highest peak of the former Soviet Union and also the highest point of Tajikistan.

Alexander published several books and many papers in scientific journals on design, kinematics, dynamics, and history of mechanisms. Several inventions and machine designs bear his name.

Starting in the 1990s, Alexander had participated enthusiastically in the activities of IFToMM (International Federation for the Promotion of Mechanism and Machine Science). He was particularly active in IFToMM Permanent Commission for History of MMS as a member from 1999 to 2007, after which he left his seat to a younger colleague while maintaining interest and contact with the commission. In 2005 he organized the very successful 5th Workshop on the History of Mechanism and Machine Science (HMMS) in Moscow, 
and he contributed to all symposia on HMMS. In 2007 along with Valentin Tarabarin, he published a book in the Springer series on HMMS on the impressive collection of models of mechanisms that the Bauman School possesses. With his help we discovered several aspects of the rich Russian history on mechanical engineering: he passed on to us his enthusiasm for models of mechanisms and also for discovering hidden parts of the history of mechanisms. He was one of the most active members of the Permanent Commission for History of MMS by participating directly with his students and collaborators at all the initiatives of the commission: events, meetings, and editorial works. Highly regarded, he was presented with a special Springer Award at the IFToMM World Congress 2011 in Guanajuato (Mexico).
Alexander was not only an excellent engineer, but also a wonderful human being. He was very cooperative, and he organized several visits of students and scholars between Russia and western Europe. IFToMM needs people like Alexander Golovin. That is why the Executive Council of IFToMM had decided to give Alexander the Dedicated Service Award. Unfortunately, he passed away before it could be presented to him.

We will miss him. 